\title{
Teleportasi Kuantum Informasi Satu Qubit dan Dua Qubit Sembarang Melalui Keadaan Gugus Empat Qubit
}

\author{
Fasya Khuzaimah, Heru Sukamto, dan Agus Purwanto \\ Departemen Fisika, Fakultas Ilmu Alam, Institut Teknologi Sepuluh Nopember (ITS) \\ e-mail:purwanto@physics.its.ac.id
}

\begin{abstract}
Abstrak-Telah dilakukan penyelidikan pada keadaan gugus dua qubit. Keadaan tersebut memenuhi tiga definisi dari keadaan gugus. Ketiga definisi dari keadaan gugus yaitu tebelit maksimal, ketahanan tinggi, dan apabila sekumpulan operator dioperasikan pada keadaan gugus tersebut maka akan menghasilkan keadaan gugus itu sendiri. Keadaan gugus dua qubit ekuivalen dengan keadaan Bell, keadaan gugus tiga qubit ekuivalen dengan keadaan GHZ, dan keadaan gugus empat qubit ekuivalen dengan keadaaan $\mid y>1234$. Selain penyelidikan pada keadaan-keadaan gugus, telah dilakukan perumusan teleportasi kuantum informasi satu qubit dan dua qubit sembarang melalui keadaan gugus empat qubit. Diperoleh hasil, keadaan satu qubit dan dua qubit sembarang dapat diteleportasikan melalui keadaan gugus empat qubit.
\end{abstract}

Kata Kunci-Gugus, Qubit, Teleportasi.

\section{PENDAHULUAN}

$\mathrm{P}$ ADA tahun 1900, Max Planck memperkenalkan kuantisasi energi kuantum mengenai radiasi benda hitam dimana perubahan energi antara materi dan radiasi bernilai diskrit. Hal tersebut kemudian menjadi lahirnya fisika kuantum. Kuantisasi energi kuantum yang diskrit kemudian dimanfaatkan dalam mesin panas kuantum [1]. Pada tahun 1926, Erwin Schrodinger memperkenalkan persamaan gelombang mengenai dualisme dari partikel-gelombang. Persamaan gelombang tersebut merepresentasikan keadaan fisis dari sistem kuantum dan dianggap sebagai teori yang lengkap. Namun, Albert Einstein, Boris Podolsky, dan Nathan Rosen (yang dikenal sebagai EPR) mempertanyakan kelengkapan teori dari persamaan gelombang tersebut. Mereka menunjukannya melalui Gedanken experiment (eksperimen pemikiran) yang diberi istilah EPR paradoks, menunjukkan bahwa persamaan gelombang dalam mekanika kuantum tidak memenuhi dua syarat kelengkapan dari suatu teori yaitu syarat elemen realitas dan syarat lokalitas. Sehingga EPR menyatakan bahwa persamaan gelombang dalam mekanika kuantum tidak lengkap [2].

Hal yang dikemukakan EPR mengenai persamaan gelombang mekanika kuantum yang mendeskripsikan dua partikel yang telah dipisahkan sangat jauh seharusnya sudah tidak berada dalam keadaan yang lokal menimbulkan gagasan kepada John
Stewart Bell untuk melakukan perumusan dengan menambahkan sebuah variabel tambahan pada persamaan gelombang mekanika kuantum untuk membuktikan hal tersebut. Namun, permasalahan EPR mengenai keadaan non lokal pada persamaan gelombang mekanika kuantum yang mendeskripsikan dua partikel yang dipisah sangat jauh tidak terbukti. Hal itu menunjukkan antara kedua partikel yang dipisahkan sangat jauh yang disebutkan dalam paper EPR tetap berada dalam keadaan lokal atau terbelit [3].

Keadaan terbelit sangat berguna dalam aplikasi fisika kuantum, salah satunya pada dalam teleportasi kuantum. Teleportasi kuantum adalah mekanisme pengiriman informasi dalam informasi kuantum. Teleportasi kuantum pertama kali dikenalkan oleh Charles Henry Bennett dan kawan-kawan pada tahun 1993. Teleportasi kuantum yang dirumuskan mereka yaitu mengenai pengiriman suatu keadaan atau informasi satu qubit sembarang dari pengirim bernama Alice menuju penerima bernama Bob melalui suatu saluran. Saluran yang digunakan yaitu keadaan terbelit EPR [4].

Namun pada paper Bennett dan kawan-kawan, saluran (keadaan terbelit) yang digunakan dalam pengiriman keadaan atau informasi masih sangat sederhana dikarenakan keadaan terbelit EPR adalah keadaan dua qubit. Teleportasi informasi satu qubit sembarang juga telah berhasil dilakukan melalui keadaan terbelit tiga qubit yaitu keadaan GHZ [5]. Namun, teleportasi informasi dua qubit sembarang tidak berhasil dilakukan melalui keadaan GHZ [6]. Lalu, bagaimana apabila keadaan atau informasi satu qubit dan dua qubit sembarang diteleportasikan dengan keadaan terbelit lain dengan qubit yang lebih banyak? Keadaan terbelit dengan banyak qubit dikenal dengan keadaan gugus (cluster). Keadaan gugus memiliki kelebihan dibandingkan keadaan terbelit lainnya karena keadaan gugus merupakan keadaan terbelit maksimal dan sulit untuk dibuat menjadi keadaan yang tidak terbelit atau keadaan terpisah [7]. Oleh karena itu, dalam penelitian dilakukan teleportasi kuantum informasi satu qubit dan dua qubit sembarang melalui saluran atau protokol keadaan gugus empat qubit dan dilakukan penyelidikan mengenai sifat atau definisi dari keadaan gugus. 


\section{TELEPORTASI KUANTUM}

Keadaan terbelit adalah suatu keadaan yang tidak dapat dipisahkan ke dalam bentuk keadaan-keadaan lain dalam perkalian langsung. Sedangkan keadaan yang sebaliknya disebut dengan keadaan terpisah. Secara umum keadaan terbelit qubit-n

$$
|\psi\rangle=\alpha_{1}\left|\begin{array}{c}
0 \cdots 0 \\
n
\end{array}\right\rangle+\alpha_{2}\left|\begin{array}{c}
0 \cdots 1 \\
n
\end{array}\right\rangle+\cdots+\alpha_{2^{n}}\left|\begin{array}{c}
1 \cdots 1 \\
n
\end{array}\right\rangle
$$

dengan tetapan kompleks $\alpha_{1}, \alpha_{2}, \ldots, \alpha_{2^{n}}$ memenuhi syarat normalisasi

$$
\left|\alpha_{1}\right|^{2}+\left|\alpha_{2}\right|^{2}+\cdots+\left|\alpha_{2^{n}}\right|^{2}=1
$$

mempunyai $2\left(2^{n}-1\right)$ derajat kebebasan. Sedangkan keadaan qubit n-plet yang dapat dipisah ke dalamn qubit tunggal [8].

$$
|\psi\rangle=\left|\psi_{1}\right\rangle \otimes\left|\psi_{2}\right\rangle \otimes \ldots \otimes\left|\psi_{2^{n}}\right\rangle
$$

Contoh dari keadaan terbelit adalah keadaan Bell atau disebut juga keadaan pasangan EPR, keadaan GHZ, dan keadaan W. Keadaan EPR tersebut adalah sebagai berikut.

$$
\begin{aligned}
& \left|\Phi^{+}\right\rangle=\frac{1}{\sqrt{2}}(|00\rangle+|11\rangle) \\
& \left|\Phi^{-}\right\rangle=\frac{1}{\sqrt{2}}(|00\rangle-|11\rangle) \\
& \left|\Psi^{+}\right\rangle=\frac{1}{\sqrt{2}}(|01\rangle+|10\rangle) \\
& \left|\Psi^{-}\right\rangle=\frac{1}{\sqrt{2}}(|01\rangle-|10\rangle)
\end{aligned}
$$

Untuk keadaan GHZ dan keadaan W adalah sebagai berikut [9].

$$
\begin{gathered}
|G H Z\rangle=\frac{1}{\sqrt{2}}(|000\rangle+|111\rangle) \\
|W\rangle=\frac{1}{\sqrt{3}}(|001\rangle+|010\rangle+|100\rangle)
\end{gathered}
$$

\section{KEADAAN GUGUS}

\section{A. Definisi Keadaan Gugus}

Suatu keadaan dikatakan sebagai keadaan gugus jika memenuhi dua definisi keadaan gugus, yaitu terbelit maksimal (maximally entangled) dan ketahanan tinggi (high persistency) [7]. Selain dua definisi tersebut, keadaan gugus juga merupakan keadaan yang apabila terdapat sekumpulan operator uniter dikerjakan pada suatu keadaan lalu menghasilkan keadaan itu sendiri [10]. Definisi-definisi ini dipenuhi oleh persamaan

$$
\left|\phi_{N}\right\rangle=\frac{1}{2^{N / 2}} \otimes_{a=1}^{N}\left(|0\rangle_{a} \sigma_{z}^{(a+1)}+|1\rangle_{a}\right)
$$

$\operatorname{dimana} \sigma_{z}^{(\mathrm{N}+1)}=1$

\section{1) Terbelit Maksimal}

Suatu keadaan memenuhi sifat terbelit maksimal adalah ketika dalam keadaan tersebut pada setiap sukunya memiliki koefisien yang sama dengan suku yang lainnya dan tiap dua qubit $j \neq k$ dan $j<k$ keadaan tersebut dapat proyeksikan ke dalam bentuk keadaan Bell dengan pengukuran lokal (transformasi uniter lokal). Keadaan Bell adalah keadaan yang terbelit maksimal dikarenakan memiliki koefisien maksimal untuk keadaan dua qubit yaitu $\frac{1}{\sqrt{2}}$ pada masing-masing sukunya dan keadaan Bell tidak dapat dipisahkan menjadi keadaan lain [7]. Misalkan untuk keadaan gugus dengan $\mathrm{N}=2$ qubit sebagai berikut.

$$
\left|\phi_{2}\right\rangle=\frac{1}{\sqrt{2}}\left(|0\rangle_{1}|-\rangle_{2}+|1\rangle_{1}|+\rangle_{2}\right)
$$

Dari dua qubit yang ada, dengan bantuan transformasi uniter lokal $I \otimes H$,

$$
(I \otimes H)\left|\phi_{2}\right\rangle=\frac{1}{\sqrt{2}}\left(|0\rangle_{1}|1\rangle_{2}+|1\rangle_{1}|0\rangle_{2}\right)
$$

dapat dilihat bahwa persamaan (26) dapat diproyeksikan ke dalam keadaan Bell pada persamaan (20).

\section{2) Ketahanan Tinggi}

Suatu keadaan dikatakan memiliki ketahanan tinggi yaitu jika keadaan tersebut sangat sulit dibuat menjadi keadaan terpisah dari keadaan yang terbelit dengan menggunakan operator uniter. Minimal banyaknya operator uniter yang dikerjakan pada keadaan gugus adalah sebagai berikut [7].

$$
P_{e_{\left|\phi_{N}\right\rangle}}=\left[\frac{N}{2}\right]
$$

Diberikan contoh untuk keadaan gugus dengan $\mathrm{N}=2$ qubit. Untuk keadaan gugus $\mathrm{N}=2$ qubit dioperasikan dengan $\left(I \otimes \sigma_{z}\right)$ dan $\left(I \otimes \sigma_{x}\right)$ dari kiri.

$$
\begin{aligned}
\left(I \otimes \sigma_{z}\right)\left|\phi_{2}\right\rangle & =\left(I \otimes \sigma_{z}\right)\left[\frac{1}{\sqrt{2}}\left(|0\rangle_{1}|-\rangle_{2}+|1\rangle_{1}|+\rangle_{2}\right)\right] \\
& =\frac{1}{\sqrt{2}}\left[|0\rangle_{1}|+\rangle_{2}+|1\rangle_{1}|-\rangle_{2}\right] \\
\left(I \otimes \sigma_{x}\right)\left|\phi_{2}\right\rangle & =\left(I \otimes \sigma_{x}\right)\left[\frac{1}{\sqrt{2}}\left(|0\rangle_{1}|-\rangle_{2}+|1\rangle_{1}|+\rangle_{2}\right)\right] \\
& =\frac{1}{\sqrt{2}}\left(-|0\rangle_{1}|-\rangle_{2}+|1\rangle_{1}|+\rangle_{2}\right)
\end{aligned}
$$

Berdasarkan persamaan (28) dan (29) dapat dilihat bahwa keadaan gugus dua qubit masih merupakan keadaan terbelit.

3) Sekumpulan Operator yang Bekerja pada Keadaan Gugus Menghasilkan Keadaan Gugus Tersebut 
Definisi ketiga dari keadaan gugus adalah keadaan yang apabila sekumpulan operator dikerjakan pada keadaan tersebut maka akan menghasilkan keadaan itu sendiri.

$$
E_{a}\left|\phi_{N}\right\rangle=\left|\phi_{N}\right\rangle
$$

dengan hubungan operator

$$
E_{a}=X_{a} \underset{b \in t \text { tan } g g a(a)}{\otimes} Z_{b}
$$

dimana $X=\sigma_{x}, Y=i \sigma_{y}, Z=\sigma_{z}[10]$.

Kita tinjau kasus untuk keadaan gugus $\mathrm{N}=2$ qubit.

$$
E_{1}=X_{1} \otimes Z_{2}
$$

maka

$$
E_{1}\left|\phi_{2}\right\rangle=\left|\phi_{2}\right\rangle
$$

Untuk

$$
E_{2}=Y_{1} \otimes Y_{2}
$$

maka

$$
E_{2}\left|\phi_{2}\right\rangle=\left|\phi_{2}\right\rangle
$$

Berdasarkan persamaan (32) dan (33) dapat dilihat bahwa keadaan gugus dua qubit memenuhi definisi ketiga keadaan gugus.

B. Keadaan-keadaan yang Ekuivalen dengan Keadaan Gugus

Dua keadaan yang dapat ditransformasikan dari satu keadaan ke keadaan yang lainnya dengan operator uniter lokal (local unitary operator) merupakan keadaan yang sama (ekuivalen). Setiap keadaan $\psi$ tertentu memiliki kelas yang sama dengan semua keadaan yang diperoleh dari keadaan $\psi$ tersebut dengan melakukan transformasi uniter lokal pada keadaan $\psi$ tersebut [11].

Dengan melakukan transformasi uniter lokal $\left(I \otimes \sigma_{Z}\right)$ pada keadaan gugus dua qubit dan dilakukan pula $(I \otimes H)$ pada keadaan Bell pada persamaan (18), $\left|\mathrm{F}^{+}\right\rangle$, maka akan menghasilkan keadaan yang sama. Sehingga, keadaan gugus dua qubit memiliki satu kelas yang sama dengan keadaan Bell dengan melakukan transformasi uniter lokal pada keadaan Bell $\left|\mathrm{F}^{+}\right\rangle$. Maka,

$$
\left|\phi_{2}\right\rangle=\left(I \otimes \sigma_{Z} H\right)\left|\Phi^{+}\right\rangle
$$

Sehingga keadaan Bell $\left|\mathrm{F}^{+}\right\rangle$berada dalam satu kelas yang sama dengan keadaan gugus dua qubit $\left|f_{2}\right\rangle$. Apabila dilakukan substitusi $|-\rangle \ll|0\rangle$ dan $|+\rangle \ll|1\rangle$ maka $\left|f_{2}\right\rangle=\left|\mathrm{F}^{+}\right\rangle$.
Dengan melakukan transformasi uniter lokal $\left(I \otimes \sigma_{Z} \otimes \sigma_{Z}\right)$ pada keadaan gugus tiga qubit dan dilakukan pula $(H \otimes I \otimes H)$ pada keadaan GHZ pada persamaan (22), $|G H Z\rangle$, maka akan menghasilkan keadaan yang sama. Sehingga, keadaan gugus tiga qubit memiliki satu kelas yang sama dengan keadaan GHZ dengan melakukan operator uniter lokal pada keadaan GHZ.

$$
\left|\phi_{3}\right\rangle=\left(H \otimes \sigma_{Z} \otimes \sigma_{Z} H\right)|G H Z\rangle
$$

Sehingga keadaan GHZ $|G H Z\rangle$ berada dalam satu kelas yang sama dengan keadaan gugus tiga qubit $\left|f_{3}\right\rangle$. Apabila dilakukan substitusi $|-\rangle \ll|1\rangle$ dan $|+\rangle \ll|0\rangle$ maka $\left|f_{3}\right\rangle=|G H Z\rangle$.

Dengan melakukan transformasi uniter lokal $\left(\sigma_{X} \otimes I \otimes \sigma_{Z} \otimes \sigma_{Z}\right)$ pada keadaan gugus empat qubit dan dilakukan pula $(H \otimes I \otimes I \otimes H)$ pada suatu keadaan $|y\rangle_{1234}$

$$
\left.\left.|y\rangle_{1234}=\frac{1}{2} \hat{\varepsilon} 0000\right\rangle+|0011\rangle+|1100\rangle-|1111\rangle\right\rangle_{\mathfrak{e}_{234}}^{\grave{y}}
$$

maka akan menghasilkan keadaan yang sama. Sehingga, keadaan gugus empat qubit memiliki satu kelas yang sama dengan keadaan $|y\rangle_{1234}$ dengan melakukan operator uniter lokal pada keadaan $|y\rangle_{1234}$.

$$
\left|\phi_{4}\right\rangle=\left(\sigma_{X} H \otimes I \otimes \sigma_{Z} \otimes \sigma_{Z} H\right)|\psi\rangle_{1234}
$$

Berdasarkan persamaan (37), keadaan gugus empat qubit $\left|f_{4}\right\rangle$ memiliki kelas yang sama dengan keadaan $|y\rangle_{1234}$ dan merupakan keadaan yang ekuivalen atau sama. Apabila dilakukan substitusi $|-\rangle \ll|1\rangle$ dan $|+\rangle \ll|0\rangle$ maka $\left|f_{4}\right\rangle=|y\rangle_{1234}$.

\section{Teleportasi Kuantum Melalui Keadaan Gugus Empat Qubit}

1) Teleportasi Kuantum Informasi Keadaan Satu Qubit Sembarang Melalui Keadaan Gugus Empat Qubit

Diberikan keadaan atau informasi satu qubit sembarang

$$
|c\rangle_{a}=a|0\rangle_{a}+b|1\rangle_{a}
$$

dengan $|a|^{2}+|b|^{2}=1$. 
Tabel 1.

Pengukuran Alice, Keadaan yang Diterima Bob, dan Operator Uniter Bob untuk Teleportasi Kuantum Keadaan Satu Qubit Sembarang

Pengukura $\quad$ Keadaan yang diterima Bob Operator Uniter Bob

\begin{tabular}{ccc}
$\mathrm{n}$ & Keadaan yang diterima Bob & Operator Uniter Bob \\
\hline$\left|\varphi_{1}\right\rangle_{a 123}$ & $\frac{1}{2}\left[\alpha|0\rangle_{4}+\beta|1\rangle_{4}\right]$ & $2 I$ \\
$\left|\varphi_{2}\right\rangle_{a 123}$ & $\frac{1}{2}\left[\alpha|0\rangle_{4}-\beta|1\rangle_{4}\right]$ & $2 \sigma_{z}$ \\
$\left|\varphi_{3}\right\rangle_{a 123}$ & $\frac{1}{2}\left[\alpha|1\rangle_{4}+\beta|0\rangle_{4}\right]$ & $2 \sigma_{x}$ \\
$\left|\varphi_{4}\right\rangle_{a 123}$ & $\frac{1}{2}\left[\alpha|1\rangle_{4}-\beta|0\rangle_{4}\right]$ & $2 i \sigma_{y}$ \\
\hline \hline
\end{tabular}

Informasi partikel satu qubit sembarang tersebut akan dikirim dari Alice menuju Bob melalui protokol dari persamaan (36) yang ekuivalen dengan keadaan gugus empat qubit yang diberikan pada Alice dan Bob. Partikel 1, 2, dan 3 diberikan kepada Alice dikarenakan Alice akan melakukan pengukuran pada partikel $a, 1,2$, dan 3 agar keadaan atau informasi $|c\rangle_{a}$ dapat diteleportasikan dari Alice menuju Bob dan partikel 4 diberikan kepada Bob karena Bob harus memiliki partikel dengan jumlah yang sama dengan jumlah partikel pada keadaan yang dikirim agar dapat menerima keadaan yang dikirim oleh Alice. Akibat dari pengukuran Alice, keadaan pada partikel $a$ akan melebur pada keadaan gugus empat qubit. Sehingga keadaan seluruh sistem menjadi sebagai berikut.

$$
\begin{aligned}
\left|\mathrm{F}_{1}\right\rangle= & |c\rangle_{a} \ddot{\mathrm{A}}|y\rangle_{1234} \\
= & \frac{1}{2}\left(a|00000\rangle_{a 1234}+a|00011\rangle_{a 1234}\right. \\
& +a|01100\rangle_{a 1234}-a|01111\rangle_{a 1234} \\
& +b|10000\rangle_{a 1234}+b|10011\rangle_{a 1234} \\
& \left.+b|11100\rangle_{a 1234}-b|11111\rangle_{a 1234}\right)
\end{aligned}
$$

Pengukuran yang dilakukan oleh Alice pada partikel $a, 1,2$, dan 3 secara langsung akan berlaku pada seluruh sistem akibat keadaan satu qubit sembarang $|c\rangle_{a}$ yang melebur pada keadaan gugus empat qubit. Pengukuran yang dilakukan Alice adalah $(\langle\varphi| \otimes I)$ pada keadaan seluruh sistem $\left|\mathrm{F}_{1}\right\rangle$ dimana pengukuran $|j\rangle$ adalah sebagai berikut.

$$
\begin{aligned}
& \left.\left|j_{1}\right\rangle_{a 123}=\frac{1}{2} \mathbf{6}^{6} 0000\right\rangle+|0110\rangle+|1001\rangle-|1111\rangle_{\dot{u}_{123}}^{\text {}} \\
& \left.\left|j_{2}\right\rangle_{a 123}=\frac{1}{2} \$ 0000\right\rangle+|0110\rangle-|1001\rangle+|1111\rangle_{\dot{q}_{123}}^{\text {}}
\end{aligned}
$$

$$
\begin{aligned}
& \left.\left|j_{3}\right\rangle_{a 123}=\frac{1}{2} \$ 0001\right\rangle-|0111\rangle+|1000\rangle+|1110\rangle_{\hat{u}_{123}}^{\grave{u}} \\
& \left.\left|j_{1}\right\rangle_{a 123}=\frac{1}{2} \hat{e} 0001\right\rangle-|0111\rangle-|1000\rangle-|1110\rangle_{\dot{q}_{123}}^{\text {}}
\end{aligned}
$$

Setelah dilakukan pengukuran $(\langle j| \ddot{A} I)\left|\mathrm{F}_{1}\right\rangle$ maka Alice akan mendapatkan hasil pengukuran. Hasil pengukuran itu merupakan keadaan yang sampai pada Bob. Namun, keadaan atau informasi yang diterima oleh Bob belum sesuai dengan keadaan $|c\rangle_{a}$ yang dikirim oleh Alice. Kemudian, Alice harus memberikan informasi melalui komunikasi klasik kepada Bob mengenai pengukuran atau operasi operator uniter yang harus dilakukan oleh Bob agar keadaan yang diterima oleh Bob sesuai dengan keadaan yang dikirim oleh Alice pada persamaan (38). Hasil pengukuran Alice atau keadaan yang sampai pada Bob dan operator uniter yang harus digunakan Bob agar keadaan yang sampai atau diterima pada Bob sesuai dengan keadaan yang dikirim oleh Alice pada persamaan (38) dirangkum pada Tabel 1.

Berdasarkan Tabel 1 dapat dilihat bahwa keadaan partikel satu qubit sembarang $|c\rangle_{a}$ dapat ditelportasikan melalui keadaan gugus empat qubit $|y\rangle_{1234}[12]$.

2) Teleportasi Kuantum Informasi Keadaan Dua Qubit Sembarang Melalui Keadaan Gugus Empat Qubit

Diberikan keadaan atau informasi dua qubit sembarang

$$
|\theta\rangle_{a b}=\alpha|00\rangle_{a b}+\beta|01\rangle_{a b}+\gamma|10\rangle_{a b}+\delta|11\rangle_{a b}
$$

dimana $|\alpha|^{2}+|\beta|^{2}+|\gamma|^{2}+|\delta|^{2}=1$. Informasi partikel dua qubit sembarang tersebut akan dikirim dari Alice menuju Bob melalui protokol dari persamaan (36) yang ekuivalen dengan keadaan gugus empat qubit yang diberikan pada Alice dan Bob. Partikel 1 dan 4 diberikan kepada Alice dikarenakan Alice akan melakukan pengukuran pada partikel $a, b, 1$, dan 4 agar keadaan atau informasi $|\theta\rangle_{a b}$ dapat diteleportasikan dari Alice menuju Bob dan partikel 2 dan 3 diberikan kepada Bob karena Bob harus memiliki partikel dengan jumlah yang sama dengan jumlah partikel pada keadaan yang dikirim agar dapat menerima keadaan yang dikirim oleh Alice. Akibat dari pengukuran Alice, keadaan $|\theta\rangle_{a b}$ akan melebur pada keadaan gugus empat qubit. Sehingga keadaan seluruh sistem menjadi sebagai berikut.

$$
\begin{aligned}
\left|\Phi_{2}\right\rangle= & |\theta\rangle_{a b} \otimes|\psi\rangle_{1234} \\
& =\frac{1}{2}(\alpha|000000\rangle+\alpha|000011\rangle+\alpha|001100\rangle \\
& -\alpha|001111\rangle+\beta|010000\rangle+\beta|010011\rangle \\
& +\beta|011100\rangle-\beta|011111\rangle+\gamma|100000\rangle \\
& +\gamma|100011\rangle+\gamma|101100\rangle-\gamma|101111\rangle \\
& +\delta|110000\rangle+\delta|110011\rangle+\delta|111100\rangle \\
& -\delta|111111\rangle)
\end{aligned}
$$


Tabel 2.

Pengukuran Alice, Keadaan yang Diterima Bob, dan Operator Uniter Bob untuk Teleportasi Kuantum Keadaan Dua Qubit Sembarang

Pengukura Operator

n Keadaan yang diterima Bob Uniter Bob

$\left|\phi_{1}\right\rangle_{a b 14} \frac{1}{4}\left[\alpha|00\rangle_{23}+\beta|01\rangle_{23}+\gamma|10\rangle_{23}+\delta|11\rangle_{23}\right] \quad 2 I \otimes 2 I$

$\left|\phi_{2}\right\rangle_{a b 14} \frac{1}{4}\left[\alpha|00\rangle_{23}-\beta|01\rangle_{23}-\gamma|10\rangle_{23}+\delta|11\rangle_{23}\right] 2 \sigma_{z} \otimes 2 \sigma_{z}$

$\left|\phi_{3}\right\rangle_{a b 14} \frac{1}{4}\left[\alpha|00\rangle_{23}-\beta|01\rangle_{23}+\gamma|10\rangle_{23}-\delta|11\rangle_{23}\right] \quad 2 I \otimes 2 \sigma_{z}$

$\left|\phi_{4}\right\rangle_{a b 14} \frac{1}{4}\left[\alpha|00\rangle_{23}+\beta|01\rangle_{23}-\gamma|10\rangle_{23}-\delta|11\rangle_{23}\right] 2 \sigma_{z} \otimes 2 I$

$\left|\phi_{5}\right\rangle_{a b 14} \frac{1}{4}\left[\alpha|01\rangle_{23}+\beta|00\rangle_{23}+\gamma|11\rangle_{23}+\delta|10\rangle_{23}\right] \quad 2 I \otimes 2 \sigma_{x}$

$\left|\phi_{6}\right\rangle_{a b 14} \frac{1}{4}\left[\alpha|01\rangle_{23}-\beta|00\rangle_{23}-\gamma|11\rangle_{23}+\delta|10\rangle_{23}\right] 2 \sigma_{z} \otimes 2 i \sigma_{y}$

$\left|\phi_{7}\right\rangle_{a b 14} \frac{1}{4}\left[\alpha|01\rangle_{23}-\beta|00\rangle_{23}+\gamma|11\rangle_{23}-\delta|10\rangle_{23}\right] \quad 2 I \otimes 2 i \sigma_{y}$

$\left|\phi_{8}\right\rangle_{a b 14} \frac{1}{4}\left[\alpha|01\rangle_{23}+\beta|00\rangle_{23}-\gamma|11\rangle_{23}-\delta|10\rangle_{23}\right] 2 \sigma_{z} \otimes 2 \sigma_{x}$

$\left|\phi_{9}\right\rangle_{a b 14} \frac{1}{4}\left[\alpha|10\rangle_{23}+\beta|11\rangle_{23}+\gamma|00\rangle_{23}+\delta|01\rangle_{23}\right] \quad 2 \sigma_{x} \otimes 2 I$

$\left|\phi_{10}\right\rangle_{a b 14} \frac{1}{4}\left[\alpha|10\rangle_{23}-\beta|11\rangle_{23}-\gamma|00\rangle_{23}+\delta|01\rangle_{23}\right] 2 i \sigma_{y} \otimes 2 \sigma_{z}$

$\left|\phi_{11}\right\rangle_{a b 14} \frac{1}{4}\left[\alpha|10\rangle_{23}-\beta|11\rangle_{23}+\gamma|00\rangle_{23}-\delta|01\rangle_{23}\right] \quad 2 \sigma_{x} \otimes 2 \sigma_{z}$

$\left|\phi_{12}\right\rangle_{a b 14} \frac{1}{4}\left[\alpha|10\rangle_{23}+\beta|11\rangle_{23}-\gamma|00\rangle_{23}-\delta|01\rangle_{23}\right] \quad 2 i \sigma_{y} \otimes 2 I$

$\left|\phi_{13}\right\rangle_{a b 14} \frac{1}{4}\left[\alpha|11\rangle_{23}+\beta|10\rangle_{23}+\gamma|01\rangle_{23}+\delta|00\rangle_{23}\right] 2 \sigma_{x} \otimes 2 \sigma_{x}$

$\left|\phi_{14}\right\rangle_{a b 14} \frac{1}{4}\left[\alpha|11\rangle_{23}-\beta|10\rangle_{23}-\gamma|01\rangle_{23}+\delta|00\rangle_{23}\right] 2 i \sigma_{y} \otimes 2 i \sigma_{y}$

$\left|\phi_{15}\right\rangle_{a b 14} \frac{1}{4}\left[\alpha|11\rangle_{23}-\beta|10\rangle_{23}+\gamma|01\rangle_{23}-\delta|00\rangle_{23}\right] 2 \sigma_{x} \otimes 2 i \sigma_{y}$

$\left|\phi_{16}\right\rangle_{a b 14} \frac{1}{4}\left[\alpha|11\rangle_{23}+\beta|10\rangle_{23}-\gamma|01\rangle_{23}-\delta|00\rangle_{23}\right] 2 i \sigma_{y} \otimes 2 \sigma_{x}$

Pengukuran yang dilakukan oleh Alice pada partikel $a, b$, 1, dan 4 secara langsung akan berlaku pada seluruh sistem akibat keadaan dua qubit sembarang $|\theta\rangle_{a b}$ yang melebur pada keadaan gugus empat qubit. Pengukuran yang dilakukan Alice adalah $(\langle\phi| \otimes I)$ pada keadaan seluruh sistem $\left|\mathrm{F}_{2}\right\rangle$ dimana pengukuran $|f\rangle$ adalah sebagai berikut.

$\left|\phi_{1}\right\rangle_{a b 14}=\frac{1}{2}[|0000\rangle+|0101\rangle+|1010\rangle-|1111\rangle]_{a b 14}$

$\left|\phi_{2}\right\rangle_{a b 14}=\frac{1}{2}[|0000\rangle-|0101\rangle-|1010\rangle-|1111\rangle]_{a b 14}$

$\left|\phi_{3}\right\rangle_{a b 14}=\frac{1}{2}[|0000\rangle-|0101\rangle+|1010\rangle+|1111\rangle]_{a b 14}$

$\left|\phi_{4}\right\rangle_{a b 14}=\frac{1}{2}[|0000\rangle+|0101\rangle-|1010\rangle+|1111\rangle]_{a b 14}$

$\left|\phi_{5}\right\rangle_{a b 14}=\frac{1}{2}[|0001\rangle+|0100\rangle-|1011\rangle+|1110\rangle]_{a b 14}$

$\left|\phi_{6}\right\rangle_{a b 14}=\frac{1}{2}[|0001\rangle-|0100\rangle+|1011\rangle+|1110\rangle]_{a b 14}$

$\left|\phi_{7}\right\rangle_{a b 14}=\frac{1}{2}[|0001\rangle-|0100\rangle-|1011\rangle-|1110\rangle]_{a b 14}$

$\left|\phi_{8}\right\rangle_{a b 14}=\frac{1}{2}[|0001\rangle+|0100\rangle+|1011\rangle-|1110\rangle]_{a b 14}$

$\left|\phi_{9}\right\rangle_{a b 14}=\frac{1}{2}[|0010\rangle-|0111\rangle+|1000\rangle+|1101\rangle]_{a b 14}$

$\left|\phi_{10}\right\rangle_{a b 14}=\frac{1}{2}[|0010\rangle+|0111\rangle-|1000\rangle+|1101\rangle]_{a b 14}$

$\left|\phi_{11}\right\rangle_{a b 14}=\frac{1}{2}[|0010\rangle+|0111\rangle+|1000\rangle-|1101\rangle]_{a b 14}$

$\left|\phi_{12}\right\rangle_{a b 14}=\frac{1}{2}[|0010\rangle-|0111\rangle-|1000\rangle-|1101\rangle]_{a b 14}$

$\left|\phi_{13}\right\rangle_{a b 14}=\frac{1}{2}[-|0011\rangle+|0110\rangle+|1001\rangle+|1100\rangle]_{a b 14}$

$\left|\phi_{14}\right\rangle_{a b 14}=\frac{1}{2}[-|0011\rangle-|0110\rangle-|1001\rangle+|1100\rangle]_{a b 14}$

$\left|\phi_{15}\right\rangle_{a b 14}=\frac{1}{2}[-|0011\rangle-|0110\rangle+|1001\rangle-|1100\rangle]_{a b 14}$

$\left|\phi_{16}\right\rangle_{a b 14}=\frac{1}{2}[-|0011\rangle+|0110\rangle-|1001\rangle-|1100\rangle]_{a b 14}$

Setelah dilakukan pengukuran $(\langle f| \ddot{\mathrm{A}} I)\left|\mathrm{F}_{2}\right\rangle$ maka Alice akan mendapatkan hasil pengukuran. Hasil pengukuran itu merupakan keadaan yang sampai pada Bob. Namun, keadaan atau informasi yang diterima oleh Bob belum sesuai dengan keadaan $|\theta\rangle_{a b}$ yang dikirim oleh Alice. Kemudian, Alice harus memberikan informasi melalui komunikasi klasik kepada Bob mengenai pengukuran atau operasi operator uniter yang harus dilakukan oleh Bob agar keadaan yang diterima oleh Bob sesuai dengan keadaan yang dikirim oleh Alice pada persamaan (44). Hasil pengukuran Alice atau keadaan yang sampai pada Bob dan operator uniter yang harus digunakan Bob agar keadaan yang sampai atau diterima pada Bob sesuai dengan keadaan yang dikirim oleh Alice pada persamaan (44) dirangkum pada Tabel 2. 
Berdasarkan Tabel 2 dapat dilihat bahwa keadaan partikel dua qubit sembarang $|\theta\rangle_{a b}$ dapat dikirim melalui keadaan gugus empat qubit $|y\rangle_{1234}[12]$.

\section{KESIMPULAN/RINGKASAN}

Dari penelitian ini, didapatkan kesimpulan

1. Keadaan gugus memiliki tiga definisi yaitu terbelit maksimal, ketahanan tinggi, dan apabila sekumpulan operator dioperasikan pada keadaan gugus tersebut maka akan menghasilkan keadaan gugus itu sendiri.

2. Keadaan gugus dua qubit ekuivalen dengan keadaan Bell, keadaan gugus tiga qubit ekuivalen dengan keadaan GHZ, dan keadaan gugus empat qubit ekuivalen dengan keadaan $|y\rangle_{1234}$.

3. Keadaan satu qubit dan dua qubit sembarang dapat diteleportasikan melalui saluran keadaan gugus empat qubit.

\section{DAFTAR PUSTAKA}

[1] Y. D. Saputra and A. Purwanto, "Mesin Carnot Berbasis Partikel Dua Tingkat di dalam Kotak Potensial Satu Dimensi,"
J. Fis. dan Apl., vol. 6, no. 1, 2010

[2] A. Einstein, B. Podolsky, and N. Rosen, "Can Quantum Mechanical Description of Physics Reality Be Considered Complate?," Phys. Rev. Lett, vol. 47, no. 777, 1935.

[3] J. S. Bell, "On The Einstein Podolsky Rosen Paradox," Physics (College. Park. Md)., vol. 1, no. 3, pp. 195-200, 1964.

[4] C. H. Bennet, G. Brassard, and et al, "Teleporting an Unknown Quantum State Via Dual Clasical and Einstein-Podolsky-Rosen Chanel," Phys. Rev. Lett, vol. 70, p. 1895, 1993.

[5] V. . Gorbachev and A. . Trubilko, "Quantum teleportation of an Einstein-Podolsky-Rosen Pair Using an Entangled ThreeParticle State," J. Exp. Theor. Phys., vol. 91, no. 5, pp. 894898, 2000.

[6] I. Rahayu, "Teleportasi Kuantum Informasi Dua Qubit Melalui Keadaan Terbelit Tiga Qubit,” Surabaya, 2017.

[7] H. J. Briegel and R. Raussendorf, "Persistent Entanglement in Arrays of Interacting Particles," Phys. Rev. Lett, vol. 86, no. 3, 2001.

[8] A. Purwanto, Diktat Mekanika Kuantum. Surabaya, 2014.

[9] M. Nakahara and T. Ohmi, Quantum Computing from Linear Algebra to Physical Realizations. USA: CRC Press Taylor \& Francis Grup, 2008.

[10] Tang and et al, "General Greenberger-Horne-Zeilinger theorem of cluster states," 2008.

[11] N. Linden and S. Popescu, "On multi-particle entanglement," 1997.

[12] X. Tan and et al, "Perfect quantum teleportation by fourparticle cluster state," Inf. Process. Lett., vol. 116, pp. 347$350,2016$. 